\title{
As políticas de valorização dos profissionais da educação como objeto da produção acadêmica recente
}

\begin{abstract}
RESUMO: Este trabalho objetiva apresentar um estudo sobre as temáticas de pesquisas realizadas no Brasil que têm como foco as políticas de valorização do profissional da educação, formuladas desde a Constituição Federal de 1988. A análise é feita a partir de consultas a resumos de teses e dissertações disponíveis no portal da CAPES, assim como de artigos publicados em periódicos que circulam na comunidade acadêmica, disponíveis no Scielo. A análise revela maior concentração dos estudos nas políticas e questões relacionadas à formação, escassez de estudos voltados para as questões profissionais e funcionais e a necessidade de maiores estudos voltados ao tema.

PALAVRAS-CHAVE: Políticas de valorização. Formação de professores. Profissionalização docente
\end{abstract}

\section{Introdução}

A partir de 1985, com o processo de redemocratização do país, desenvolveu-se um período marcado pela participação de diversos movimentos sociais, bem como dos sindicatos e outras organizações sociais na busca por mais direitos, e da participação do cidadão na vida política brasileira. Por conseguinte, as lutas sociais se intensificaram num processo em que se exigiam direitos sociais igualitários e melhores condições de vida e de trabalho das diferentes camadas sociais. Por seu turno, reivindicações eram debatidas e apresentadas pelas diversas categorias profissionais. É no bojo dessas discussões que emergem e se solidificam as lutas dos profissionais da educação no sentido de que sejam conseguidos novos direitos e de serem asseguradas melhores garantias para o exercício das suas profissões. Dos debates travados a partir daí, pode-se perceber que alguns avanços têm sido conquistados no campo do direito, por esse grupo ocupacional no Brasil.

Vale destacar que o conjunto de reformas educacionais empreendidas pelo governo brasileiro nos anos 90 tem colocado a ampliação das oportunidades educacionais e a melhoria da qualidade do ensino como ligadas ao desempenho dos profissionais da educação. Alguns pontos da legislação, que dão suporte à implementação dessas reformas, podem demonstrar as garantias estabelecidas para a efetivação de políticas de valorização do magistério público da Educação Básica. Assim, a Constituição

\section{Maria Couto Cunha}

Professora Adjunta da Faculdade de Educação da UFBA mcouto@ufba.br

Cristiane da Conceição Gomes Graduanda em Pedagogia da Faculdade de Educação da UFBA cris_ufba2002@yahoo.com.br 
Federal de 1988, no seu artigo 206, fixa, dentre os princípios com os quais deve ser ministrado o ensino no Brasil, o da "valorização dos profissionais do ensino, garantidos, na forma da lei, planos de carreira para o magistério público, com piso salarial profissional e ingresso exclusivamente por concurso público de provas e títulos [...]" (BRASIL, 1988).

As políticas de valorização do profissional da educação básica é mais especificada na LDB/96. Nessa legislação, constam nove artigos dedicados, exclusivamente, aos profissionais da educação básica, sendo que, na sua maioria, tratam das exigências de sua formação. Mas, além disso, estabelece, no artigo 67, que os sistemas de ensino devem promover a valorização desses profissionais através dos estatutos e planos de carreira, garantindo o ingresso na carreira exclusivamente por concurso público de provas e títulos, licenciamento remunerado para formação continuada, piso salarial profissional, progressão funcional baseada em titulação ou habilitação e avaliação de desempenho, período reservado para estudos, além das condições adequadas de trabalho.

Os mecanismos de valorização do profissional da educação também se encontram fixados na Lei no 9.424/96 que regulamentou o Fundo de Manutenção e Desenvolvimento do Ensino Fundamental e Valorização do Magistério (FUNDEF). Além de assegurar que, pelo menos sessenta por cento dos recursos do Fundo devem ser utilizados para a remuneração dos profissionais do magistério, em efetivo exercício de suas atividades no ensino fundamental público, fixa a permissão, no seu art. $7^{\circ}$, de utilização de parte desses recursos, nos primeiros cinco anos, na capacitação de professores leigos (BRASIL, 1996a). Também no art $9^{\circ}$ dessa lei, é previsto que os Estados, o Distrito Federal e os Municípios deverão dispor de novo Plano de Carreira e Remuneração do Magistério, de modo a assegurar: a remuneração condigna dos professores do ensino fundamental público, em efetivo exercício do magistério; o estímulo ao trabalho na sala de aula; e a melhoria da qualidade do ensino (BRASIL, 1996a). Neste quesito, o Conselho Nacional de Educação, através da Resolução CEB/ CNE, $n^{\circ}$ 3, de 08 de outubro de 1997, fixa as diretrizes para esses novos planos de carreira e de remuneração para o magistério público, incluindo, dentre outras determinações a experiência mínima de dois anos em docência para o exercício de quaisquer das funções do magistério que não seja a docência e a 
obrigatoriedade dos sistemas em promover concursos quando comprovada a existência de vagas.

No Plano Nacional da Educação, aprovado pela Lei n. 10.172, de janeiro de 2001, a valorização dos profissionais da educação também constitui uma das prioridades, destacando-se a atenção que deve ser dada à formação inicial e continuada, especialmente dos professores, assinalando que faz parte dessa valorização a garantia das condições adequadas de trabalho, entre elas, o tempo de estudo e preparação das aulas, salário digno, com piso salarial e carreira de magistério. (BRASIL, 2001)

Há que se considerar que estes diplomas legais vão ao encontro de muitos dos anseios, das bandeiras de luta e das reivindicações que caracterizaram as manifestações dessa categoria desde as décadas de 70 e 80 e, de certo modo, inspiraram as reformas educacionais que se procederam nos anos 90. Diante disto, cumpre, então, indagar: em que sentido os direitos e garantias fixados na legislação estão realmente sendo efetivados? Em que medida os educadores e pesquisadores do campo da educação estão acompanhando e analisando a consecução dos objetivos dessas políticas? Que aspectos da profissionalização docente essas políticas têm considerado? Quais os entraves que existem na sociedade brasileira para se alcançar uma verdadeira valorização do profissional da educação?

É buscando compreender o contexto em que situa estas questões que este artigo apresenta uma análise dos temas correntes da produção acadêmica sobre as políticas de valorização do profissional da educação que vem sendo implementadas desde a Constituição Federal de 1988 até os dias atuais.

Neste sentido, buscou-se levantar as principais temáticas constantes nas reflexões, discussões e proposições que a comunidade acadêmica desenvolveu através de pesquisas que fundamentaram a elaboração de teses de doutorado, dissertações de mestrado e de artigos publicados em revistas especializadas de educação do país, no período de 1988 a 2005. As informações foram levantadas a partir do portal de periódicos da CAPES e do sistema Scielo, sendo capturados os resumos desses trabalhos na série histórica considerada, sendo alguns artigos analisados na íntegra, o que possibilitou aprofundar um pouco nas análises das temáticas por eles trabalhadas. No caso das teses e dissertações, foram utilizadas na busca e catalogação algumas palavras-chave que dessem 
conta do tema pesquisado ou de campos do conhecimento próximos a ele. Já com relação aos artigos, foram analisados todos os resumos disponíveis no Scielo relativos às revistas de educação do país. Com isso foram selecionados 92 trabalhos que foram classificados em categorias, tendo como base principal os mecanismos de valorização dos profissionais da educação que se apresentam nos instrumentos legais definidores dessa política.

Procede-se à análise dos achados deste trabalho de catalogação e classificação analítica, tentando evidenciar as tendências das problematizações correntes entre os pesquisadores dessa área no Brasil.

\section{Uma Visão Geral das Temáticas}

Do total de 92 títulos que se relacionam ao objeto deste estudo, oito constituíam-se de teses do doutorado, quarenta e seis dissertações de mestrado defendidas em universidades brasileiras e trinta e oito artigos publicados em seis periódicos especializados em educação. Grande parte do material analisado foi publicada na revista Educação \& Sociedade (71\%) e na revista Cadernos de Pesquisa (13\%).

Tabela 1 - Distribuição dos resumos pesquisados por categorias analisadas

\begin{tabular}{|c|c|c|}
\hline Conteúdo & $N^{\circ}$ & $\%$ \\
\hline \multicolumn{3}{|l|}{ FORMAÇÃO PROFISSIONAL } \\
\hline Formação inicial & 27 & 29,4 \\
\hline Formação continuada e/ou em serviço e saberes docentes & 29 & 31,5 \\
\hline Formação e novas tecnologias & 5 & 5,4 \\
\hline Subtotal & 61 & 66,3 \\
\hline \multicolumn{3}{|l|}{ PROFISSIONALIZAÇÃO, CARREIRA E CONDIÇÕES FUNCIONAIS } \\
\hline Profissionalização e identidade & 13 & 14,1 \\
\hline Planos de carreira & 1 & 1,1 \\
\hline Certificação e avaliação & 2 & 2,2 \\
\hline Participação política & 4 & 4,4 \\
\hline Condições de trabalho e seus efeitos & 11 & 11,9 \\
\hline Subtotal & 31 & 33,7 \\
\hline Total Geral & 92 & 100,0 \\
\hline
\end{tabular}

Fonte: Pesquisa das autoras 


\begin{tabular}{|c|c|c|}
\hline Conteúdo & $\mathrm{N}^{\circ}$ & $\%$ \\
\hline \multicolumn{3}{|l|}{ FORMAÇÃO PROFISSIONAL } \\
\hline Formação inicial & 27 & 29,4 \\
\hline Formação continuada e/ou em serviço e saberes docentes & 29 & 31,5 \\
\hline Formação e novas tecnologias & 5 & 5,4 \\
\hline Subtotal & 61 & 66,3 \\
\hline \multicolumn{3}{|l|}{ PROFISSIONALIZAÇÃO, CARREIRA E CONDIÇÕES FUNCIONAIS } \\
\hline Profissionalização e identidade & 13 & 14,1 \\
\hline Planos de carreira & 1 & 1,1 \\
\hline Certificação e avaliação & 2 & 2,2 \\
\hline Participação política & 4 & 4,4 \\
\hline Condições de trabalho e seus efeitos & 11 & 11,9 \\
\hline Subtotal & 31 & 33,7 \\
\hline Total Geral & 92 & 100,0 \\
\hline
\end{tabular}

Analisados os resumos, estes foram selecionados e classificados conforme categorias, considerando os enfoques trabalhados e a natureza do objeto investigado, tendo sempre em mente os mecanismos de valorização do profissional da educação evidenciados nas políticas educacionais, constantes na legislação. Com isso, obteve-se a classificação em dois blocos, que na análise se desdobraram em categorias, conforme tabela acima. Levando-se em conta os aspectos considerados importantes nas políticas de valorização do profissional da educação, a maior parcela dos trabalhos consultados na pesquisa se concentra nas questões ligadas à formação. Percebe-se um déficit em termos quantitativos de estudos que poderiam analisar e discutir aspectos importantes da profissionalização, direitos, garantias e condições de trabalho dessa categoria. Estudos que também dessem conta de avaliar as ações do governo na direção da efetividade dessas políticas prescritas na legislação.

\section{Os Trabalhos que Discutem a Formação Profissional}

A formação dos profissionais da educação é um dos fatores de valorização explícito nos marcos legais e, também, item de muita discussão em torno da implementação das políticas educacionais formuladas no Brasil. Para efetuar a síntese dos conteúdos dos trabalhos nesse sentido foram consideradas três 
categorias: formação inicial, formação continuada e/ou em serviço e aproveitamento dos saberes docentes, e relacionada com as novas tecnologias. Através da quantidade de trabalhos encontrados nessas categorias pode-se perceber a importância que os estudos conferem à formação inicial e à continuada que se constituem momentos singulares da formação docente. Outros estudos já aparecem estabelecendo a relação da formação com as novas tecnologias levando em conta as transformações que surgem do desenvolvimento tecnológico e da necessidade da inserção dessas tecnologias no ambiente escolar assim como das ações necessárias com vistas ao preparo do professor para lidar com essas inovações.

Formação inicial

Nessa categoria estão presentes 27 trabalhos, distribuídos em três subcategorias para análise. A primeira diz respeito aos estudos que fazem uma abordagem dos condicionantes e desafios existentes para a formulação das políticas de formação dos profissionais da educação. Nessa linha, são apresentados 16 trabalhos com os seguintes conteúdos: análises das relações/interferências de organismos internacionais na definição dessas políticas; as perspectivas de formação desses profissionais; análises das propostas curriculares dos cursos das licenciaturas; a visão do professor sobre as políticas de formação; discussão sobre o lócus de formação para o professor. Nesses trabalhos aparece o embate entre as proposições das entidades representativas dos educadores e as definições e determinações do governo brasileiro, no que se refere à formulação das políticas de formação de professores.

Os debates em torno dessas questões têm ocupado a atenção da comunidade acadêmica, que tem relacionado a implementação das políticas de formação e valorização dos profissionais da educação, assim como das políticas educacionais em geral, aos movimentos da globalização, da refuncionalidade do capitalismo e das novas relações de trabalho, que têm nos organismos internacionais seus principais protagonistas. Por conseguinte, as políticas de ajustes dos países como o Brasil a esse novo cenário mundial, têm resultado na implantação de um conjunto de reformas que implicam em altos custos sociais para amplos segmentos da população. Neste sentido, apesar de se constituir prioridade, nos discursos oficiais, a educação escolar sofre as conseqüências do 
descaso das ações sucessivas de desvalorização social e econômica dos profissionais da educação e do desmantelamento da educação superior. (BRZEZINSKI, 2002)

As análises dos autores demonstram que as políticas de formação não fortalecem o profissionalismo e a identidade do professor como categoria ocupacional. São constantes as medidas que direcionam a formação do pedagogo ou do professor em uma diversificação de cursos, inclusive em ambientes não universitários. Outra crítica focaliza a política de formação pedagógica aligeirada a portadores de diploma de nível superior de outras áreas, incidindo, assim, no enfraquecimento da identidade do professor. Nos estudos e pesquisas consultados nesta subcategoria são criticadas, desta forma, as propostas de cursos aligeirados e de baixo custo para atendimento às políticas oficiais que tem como resultado a formação do professor como tarefeiro, inviabilizando a constituição de sua identidade. Com isso, há que se definir a especificidade da ação docente, o que implica no cuidado com a sua formação e, conseqüentemente, na construção da identidade desse profissional. (KUENZER, 1999)

Nesse sentido, a formação desses profissionais fora das universidades vai inviabilizar a construção de sua identidade como cientista da educação. Por outro lado, considerando os novos cenários, as novas relações de trabalho exigem uma nova pedagogia, novas competências para trabalhar com as diferenças, novas capacidades para suprir a deficiência cultural e cognitiva dos alunos das classes populares, inclusive para articular as várias áreas do saber como ciência, cultura e trabalho. Para a citada autora, as reformas que incluem o novo modelo de formação de professores não levam em consideração esses aspectos. Segundo as recomendações dos organismos externos, que priorizam a universalização do ensino fundamental, as políticas voltam-se para preparar professores com a formação aligeirada e de baixo custo para o incentivo à formação específica e à formação pedagógica desse profissional em espaços não universitários, com o risco, inclusive, de terceirizar a realização de cursos, ou até desenvolvêlos de forma virtual. (KUENZER, 1999, p. 181)

Numa outra subcategoria, seis trabalhos explicitam as dificuldades e desafios para a formação de professores da educação infantil $e$ séries iniciais do ensino fundamental. Utilizando-se de argumentos semelhantes aos dos autores acima mencionados, esses estu- 
dos discutem e analisam modelos de cursos de formação do profissional da educação que atendem a essas etapas da educação básica, tendo em vista as mudanças legais e as reformas delas advindas neste sentido. Nesses estudos, é acentuada a necessidade de uma formação sólida para os docentes que atendem a essa demanda. Criticam as orientações oficiais que levam a criar os Institutos Superiores de Educação para a oferta desses cursos, possibilitando o aligeiramento da formação e a falta de comprometimento com a qualidade, criando, assim, uma diversidade de formação de professores, o que incide no enfraquecimento da identidade profissional desses futuros professores.

Uma terceira subcategoria agrupa os trabalhos que discutem a formação inicial nos cursos de Pedagogia e das licenciaturas. Cinco trabalhos analisam o papel do pedagogo, sua formação, atuação e suas condições de trabalho e a centralidade dos cursos de Pedagogia e das licenciaturas como materialização das políticas de formação do profissional da educação nas instituições federais do ensino superior. Para autores como Márcia Ângela Aguiar e Márcia Melo (2005), as faculdades, os centros de educação, os departamentos de educação ocupam um lugar central na criação de uma cultura pedagógico-docente que deve expressar um projeto políticoinstitucional e acadêmico mais amplo da instituição universitária a ser construído de forma conjunta, pautado por uma concepção sociohistórica de educação na perspectiva da cidadania e emancipação humana do profissional. Para essas autoras, essas políticas de formação devem ser ancoradas numa base comum que deve se manifestar em todos os processos e práticas formativas no interior das universidades e se materializar nos currículos dos cursos, de forma a contribuir para o desenvolvimento dos profissionais da educação e da sua profissionalidade e profissionalização, com vistas à construção de saberes necessários à sua profissão e ao processo de desenvolvimento da sua autonomia (AGUIAR; MELO, 2005). Para elas, na perspectiva sociohistórica da educação, acima referida, a construção desses saberes se efetiva no contexto da indissolubilidade entre ensino, pesquisa e extensão e da sedimentação/dinamização dessa cultura.

Vê-se, portanto, que tais autoras focalizam pontos já mencionados neste artigo, encontrados na literatura analisada, que dizem respeito ao lócus da formação do profissional da educação: a universidade. Neste sentido apontam para a necessidade de cons- 
trução de um projeto coletivo de formação entre as instituições de ensino, que dê conta da complexidade dessa formação e da necessidade de fortalecimento do profissionalismo da categoria de professores e pedagogos. Por outro lado, a este respeito, a Associação Nacional de Formação do Profissionais da Educação (ANFOPE) defende a transformação das atuais licenciaturas em cursos de graduação plena de formação de professores, à luz da pedagogia e das ciências da educação, visando a formação crítica do educador, capaz de transformar as condições atuais do trabalho pedagógico na educação básica. (ASSOCIAÇÃO NACIONAL PELA FORMAÇÃO DOS PROFISSIONAIS DA EDUCAÇÃO, 2004)

Formação continuada e/ou em serviço e saberes docentes

Esta categoria de estudos reúne vinte e nove pesquisas. Numa primeira abordagem, os estudos se concentram na análise de experiências de formação, tendo como resultados algumas propostas de programas. Em geral, são feitas críticas aos programas oficiais, acusados de fragmentação e sem ligação com a experiência do professor, no que redunda na fraca repercussão dos cursos na prática docente. Alguns trabalhos analisam os reflexos positivos dos programas de municipalização nas novas proposições de formação continuada. De fato, as ações de descentralização da educação, de reforço a educação municipal e de valorização do magistério, especialmente do ensino fundamental, a exemplo da implementação do FUNDEF, promoveram mudanças importantes na formação e valorização dos profissionais das redes municipais, a partir do final dos anos 90, especialmente nos municípios das regiões mais pobres do país. Por outro lado, pode-se considerar que a política do FUNDEF pouco alterou a realidade dos professores dos grandes centros urbanos já que o fundo não propiciou aumento do financiamento da educação e, sim, uma melhor distribuição dos recursos entre estados e municípios, sem contribuição financeira efetiva da União, nem o seu comprometimento político com a valorização profissional e salarial dos professores da Educação Básica.

Por outro lado, verifica-se preocupações com a formação continuada para a educação infantil. Foram feitas análises da concepção dos professores dessa etapa da educação sobre a elaboração de propostas de formação, assim como das condições necessárias para o processo de construção e reconstrução da prá- 
tica reflexiva desse profissional. Foram realizados estudos que fazem a ligação entre formação e atuação desse profissional e, ainda, outros, que fazem críticas aos programas de formação continuada para professores alfabetizadores, caracterizada, por eles como um exercício apenas de "repasse de conhecimentos", sem orientação para a prática. Em geral, os cursos de formação continuada de professores deste nível não oferecem os suportes teóricos e técnicos necessários para o desenvolvimento dessa etapa da educação.

Por outro lado, as secretarias municipais de educação que são as principais responsáveis para a gestão pedagógica nesse nível, não contam com pessoal qualificado para desenvolver um trabalho de apoio técnico e operacional aos professores. Soma-se a isto, ainda, as dificuldades financeiras sofridas pelas prefeituras para que sejam dados o suporte pedagógico e os recursos materiais conforme a especificidade e importância dessa oferta de ensino. Estudos têm demonstrado que a escolha dos conteúdos, a definição sobre as práticas pedagógicas na educação infantil não contam com a participação dos professores, como principais sujeitos dessas práticas. Além disso, não se baseiam nas realidades sócio-culturais das crianças. Esta situação só se reverteria a partir da implementação de programas de capacitação dos técnicos e professores afinados com diretrizes formuladas pelos próprios profissionais e com as condições materiais e financeiras adequadas a essa finalidade.

Em uma outra abordagem dentro desta subcategoria, alguns trabalhos se dirigem à análise da formação continuada e/ou serviço de professores leigos. Os estudos que tratam dessa questão abordam os aspectos como: a crítica à natureza das políticas oficiais de formação; a crítica às políticas oficiais de formação à distância, acusando-as de estratégias de formação de contingentes de reserva formados por habilitados; inexistência de política de qualificação para o profissional docente leigo na zona rural; análise de condições possíveis para mudanças pessoais e profissionais como resultado de um programa de formação em serviço e análise de experiências que tratam da necessidade de valorização dos saberes e experiências dos docentes leigos na sua formação continuada.

A relação formação continuada e saberes docentes construídos na prática do professor está presente em doze traba- 
1hos que se agrupam em uma terceira subcategoria. São pesquisadas experiências que ressaltam a preocupação com a valorização do saber cotidiano e da prática do professor na formulação e implementação das ações de formação, assim como o efeito da formação continuada que se baseia na prática desse profissional para o sucesso pedagógico na sala de aula. São pesquisadas as representações dos professores sobre sua formação e atuação docente. Outros estudos se concentram sobre os saberes adquiridos na prática que orientam a atuação do coordenador pedagógico. O eixo que orienta tais preocupações se coloca, portanto, em um pressuposto muito importante, qual seja, o de considerar o professor como sujeito da sua prática, de dotá-lo das condições para decidir sobre os conteúdos, valores, os elementos culturais que deve trabalhar com os seus alunos, assim como as formas através das quais eles desenvolvem seu trabalho pedagógico. Fica implícita nesses estudos, a necessidade de dar espaço aos professores, para que sejam ouvidas as suas vozes como sujeitos da atividade educativa e como participantes ativos da sua formação.

Formação e novas tecnologias

A terceira categoria dentro deste bloco de estudos que tratam da formação profissional analisa o uso das tecnologias da informação e comunicação em programas de formação de professor, e o uso dessas tecnologias na prática docente. Um estudo procurou delinear caminhos para a formação de professores, tendo como eixo teórico a integração das novas tecnologias ao campo educacional. Outro trabalho analisou as percepções dos docentes em relação às tecnologias da informação, especialmente, o computador e a internet.

Levando em conta a importância que se reveste os novos meios de comunicação e informação e as múltiplas possibilidades que esses meios oferecem para o processo da aprendizagem e a produção e veiculação do conhecimento é de se reconhecer a necessidade de pesquisas nessa área, sobretudo que enfatizem novas formas de condução do trabalho pedagógico em suas múltiplas materializações. Daí a importância de se vincular esta discussão à análise e à implementação dos programas de formação inicial e continuada do professor da educação básica e do pedagogo e, por extensão, às questões ligadas ao seu desempenho, autonomia, por fim, a sua valorização como profissional. 


\section{Questões de Profissionalização, Carreira e Condições Funcionais do Magistério}

Este bloco potencializa uma discussão sobre os aspectos menos difundidos sobre a política de valorização do magistério público no Brasil. Para iniciar, é interessante apontar alguns dos aspectos em questão, defendidos pelas entidades representativas dos professores, quais sejam: redução do número de alunos em sala de aula na educação básica; valorização do trabalho docente através da instituição de jornada única em uma única escola; atribuição de salários justos e compatíveis com a jornada de traba1ho; estabelecimento de programas de formação continuada em parceria com as universidades públicas; licença remunerada dos professores para formação continuada; e, criação de centros de formação de educadores em municípios e estados geridos pelos educadores (ASSOCIAÇÃO NACIONAL DE FORMAÇÃO DOS PROFISSIONAIS DA EDUCAÇÃO, 2004). Nesse sentido, abordamos algumas questões encontradas que se relacionam com as apontadas acima e que estão intimamente ligadas à políticas de valorização do profissional da educação.

\section{Profissionalização e identidade}

Treze trabalhos encontrados nesta pesquisa se ocupam especificamente dessa temática. Discutem o papel do professor na dimensão social e histórica da profissão, os aspectos que constituem ou devem constituir a sua identidade, chegando a sinalizar a necessidade de construção de propostas de formação que levem ao fortalecimento dessa identidade, acentuando a importância de se valorizar os saberes adquiridos no exercício da profissão. E analisam os elementos mais significativos para a vida pessoal e profissional do professor que podem contribuir para um trabalho bem sucedido na docência.

Nestas pesquisas são desenvolvidos estudos das representações dos professores sobre a sua prática ou são analisadas as suas experiências através das suas histórias de vida. Em alguns desses trabalhos são discutidos os fatores que levam à desvalorização da carreira e à insatisfação profissional. Estes trabalhos chamam a atenção para fatores muito importantes que levam à compreensão das questões atuais ligadas à identidade e profissionalização do professor e do profissional da educação, em geral.

62 R. Faced, Salvador, n.12, p.51-70, jul/dez. 2007 
Para que haja a valorização do profissional da educação, é preciso que seja definida a sua identidade profissional. Para Nóvoa, além da formação inicial e continuada, para o processo de profissionalização do professorado, são necessários outros componentes: o exercício de atividades em tempo integral, o estabelecimento de um suporte legal para o exercício da profissão, um conjunto de normas e valores e de um corpo de conhecimentos e técnicas de instrumentação, que identifiquem o profissional, a constituição de associações de classe e o controle de admissão dos membros pelos próprios pares (NÓVOA, 1991 apud BRZEZINSKI, 2002). Isto concorre a uma política de valorização do trabalho docente.

Muitos desses elementos importantes para a identidade profissional do professor e do pedagogo não estão presentes na realidade brasileira. Mesmo em termos de requisitos para o ingresso na carreira, a legislação vigente não colabora para a constituição desse profissionalismo. É só verificar o que a LDB 9394/96 determina no seu artigo 61, quando permite adotar a capacitação em serviço e o aproveitamento de formação e experiência em serviço na formação do professor, assim como o aproveitamento da formação e experiências anteriores como fórmulas capazes de habilitar o professor. Assim, a própria legislação contribui para o processo de esfacelamento da identidade do educador. Na realidade, o que consta na legislação em termos do perfil esperado do professor é uma concepção fragmentada da sua identidade, que se encontra dispersa em várias partes dos diplomas legais. (BRZEZINSKI, 2002)

Menga Ludke e Luis Boing também tocam nesta questão ao analisar o processo de precarização da profissão docente. Estes autores alertam para a dificuldade de se conceituar a profissão do magistério. A diversidade de cursos e de modelos de formação, a divisão da ocupação docente em "corpos" que representam realidades distintas, considerando níveis e etapas de ensino, os limites da autonomia do grupo ocupacional, submetido a um sistema distinto subordinado à regulação pelo Estado, dentre outros fatores, acabam por determinar diferenças e hierarquias, num corpo docente que não constitui uma força una como acontece com outras profissões. Outros autores também apontam a divisão que se estabelece dentro do grupo, que separa professores e pesquisadores, assim como o surgimento das ciências da educação como 
fatores de enfraquecimento do campo pedagógico, reduzindo-o a um plano secundário. Com isso, pode-se perceber a repercussão das políticas de formação dos profissionais da educação nesse processo de destruição da sua identidade.

Ao retirar da universidade a formação do professor, o governo nega a sua identidade como cientista e pesquisador, ao mesmo tempo em que nega à educação o estatuto epistemológico de ciência, reduzindo-a a mera tecnologia, ou ciência aplicada, ao mesmo tempo em que reduz o professor a tarefeiro, chamando de profissional [...]. (KUENZER, 1999, p.182)

Outros autores são ainda mais críticos em relação aos males que as políticas educacionais recentes têm provocado na profissionalização docente. Para Hypólito (1999), o que se verifica é que o profissionalismo docente no Brasil foi pouco alcançado, mas existe como realidade discursiva, como sonho prometido sempre arremessado a um futuro distante e indeterminado. Para este autor, pode-se identificar, no discurso oficial de muitos governantes, uma aceitação formal da necessidade de uma profissionalização docente,

[...] porém,com visíveis indícios de que esse discurso vem sendo utilizado mais para criar uma ilusão de que passos significativos estão sendo dados nesta direção, quando na realidade, o que se tem testemunhado são políticas educacionais e administrativas que contribuem mais para uma negação do que para uma afirmação das práticas profissionais. (HYPÓLITO, 1999, p. 82)

Em outro sentido, as questões ligadas à identidade profissional do professor e pedagogo se materializam através do fenômeno da precarização do trabalho docente e das suas repercussões sobre as práticas curriculares. Um primeiro fator pode ser assim considerado. Seria de se pensar que o crescimento da escolarização no Brasil nas últimas décadas levasse a uma maior demanda de profissionais da educação e, conseqüentemente, na valorização do seu trabalho. Na realidade, o crescimento das redes de ensino e a carência de profissionais capacitados para a ampliação dessa oferta ocasionaram o recrutamento de professores sem a devida formação. Esta situação ainda vigora no Brasil de hoje, o que concorre para a precarização do trabalho docente, pela falta de domínio dos conteúdos e de formação pedagógica desses professores. (SAMPAIO; MARIN, 2004)

64 R. Faced, Salvador, n.12, p.51-70, jul/dez. 2007 
Uma das formas mais visíveis da precarização do trabalho do professores refere-se ao salário recebido pelo tempo de dedicação às suas funções, sobretudo, por aqueles que atuam nas redes públicas de ensino. A precarização por essa via significa a pauperização da vida pessoal do professor nas suas relações entre vida e trabalho, principalmente no que tange ao acesso aos bens culturais, imprescindíveis para a sua atualização e para o planejamento e execução das suas atividades pedagógicas. Além destas questões, os autores Sampaio e Marin apontam como elementos de precarização do trabalho docente que incidem nas práticas curriculares, as condições de trabalho, geralmente presentes na organização escolar como: a carga horária excessiva e diversificada entre os professores, o tamanho das turmas e a rotatividade dos professores.

Todas estas questões concorrem para a desvalorização da carreira docente e para tornarem efetivas as dificuldades da identidade profissional da categoria ocupacional que lida com a educação.

Plano de carreira do magistério público

Sobre este importante mecanismo de valorização dos profissionais da educação, reservado em lei, na pesquisa que se empreendeu para levantar a produção acadêmica sobre as políticas de valorização do profissional da educação foi encontrado apenas um trabalho. O mesmo procurou analisar a política de valorização do magistério adotada por um município brasileiro, buscando identificar a perspectiva adotada pelo poder local sobre a questão, bem como suas repercussões na elaboração do Plano de Carreira e Remuneração do Magistério Municipal. Vê-se, portanto, que este não tem sido um tema focalizado nos estudos deste campo acadêmico na série de anos considerados nesse levantamento.

Esse plano é um importante ponto de valorização do magistério público, pois trata de questões básicas da profissão docente, dentre estas o salário que além de incentivo a profissão se constitui em oportunidade de crescimento profissional e pessoal. Assim, segundo Monlevade (2002, p. 269), "o salário não é determinante da valorização do professor. Mas ele expressa, simboliza, manifesta como que um grau de valorização. E o sustenta materialmente." 
Certificação e avaliação de desempenho do professor

Dois trabalhos se dedicaram a essa temática. O primeiro analisando o Governo Lula no campo das políticas de formação de professores, tratadas como continuidade das políticas de certificação e regulação do trabalho docente. O segundo, analisando as repercussões das novas políticas no campo educacional, especialmente, na formação de professores na cultura de desempenho.

Nesse assunto é importante ressaltar que a avaliação de desempenho se constitui em grande desafio para a organização da carreira do magistério da educação básica (ABREU; BALZANO, 2001, p. 219). Além disso, não é bem recebida pelo professor, pois depende de uma organização criteriosa dos objetivos e procedimentos desta avaliação. Quanto a certificação, a legislação vigente propiciou a propagação de cursos para certificação profissional do magistério público ao concluir pela obrigatoriedade de habilitação para a docência. Devido a falta de maiores recursos na área, alguns programas foram criados para a certificação desses profissionais para atendimento aos preceitos legais, mas que necessariamente não atendem aos verdadeiros objetivos de melhoria do desempenho docente, configurando-se mais como um recurso de apenas titulação.

\section{Participação política do professor}

Essa subcategoria aborda algumas dimensões da participação do professor, contando com quatro contribuições. Uma das dimensões, a política, é tratada por um estudo sobre o professor enquanto profissional que se forma na organização sindical. Outra, numa dimensão mais pedagógica, procurando mostrar a necessidade de se conceber o professor como sujeito de fazer e saber mediado pelas condições de trabalho, valores e contexto social e, também, como aquele que busca alargar o seu poder e o reconhecimento de sua especialidade pelo Estado, destacando a importância e força da sua atuação organizada. Por fim, uma análise da implementação da gestão democrática em duas escolas públicas, focaliza a posição dos professores diante do provimento do cargo de diretor escolar.

Diante dessas situações, pode recorrer a João Monlevade que, dentre outras considerações, afirma que a valorização do professor vem de três fontes, acima de outros fatores: formação inte- 
lectual e ética do professor para os desafios do seu trabalho (...); constituição de uma identidade profissional, dada não só pelo saber científico como pela luta e organização sindical; e decisão política do Estado de tirar os entraves que impedem o pagamento de salários dignos, calculado para jornada integral e dedicação exclusiva do professor na escola (MONLEVADE, 2000, p. 272). Essas questões fazem parte de lutas históricas dos professores e ainda carecem de maiores iniciativas do governo para o setor, assim como de investimentos de pesquisas pela comunidade acadêmica.

Condições de vida e de trabalho do professor e seus efeitos

Dentro desta categoria foram encontrados 11 estudos que procuram evidenciar as seguintes situações: as condições de trabalho da escola particular; o abandono do magistério; o stress do professor da educação infantil; a situação do trabalho docente e suas conseqüências sobre as práticas curriculares; motivos pelos quais os professores persistem no exercício profissional, dadas as precárias condições de trabalho; a precarização do trabalho docente; a perda do prestígio social do professor e sua atuação profissional; a pobreza das políticas educativas e dos programas de formação; a desvalorização dos profissionais da educação em termos de salários; os efeitos do FUNDEF sobre as funções e a qualificação docente no contexto do regime de colaboração entre os entes federados, analisando os efeitos desse Fundo sobre a valorização do magistério via plano de carreira e salário.

As condições de trabalho do professor na atualidade, segundo Dalila Oliveira (2004), envolve o arrocho salarial, a inadequação ou mesmo ausência, em alguns casos, de planos de cargos e salários, a perda de garantias trabalhistas e previdenciárias oriunda dos processos de reforma do Aparelho de Estado, que têm tornado cada vez mais agudo o quadro de instabilidade e precariedade do emprego no magistério público.

\section{Algumas Considerações Finais}

À guisa de conclusão, podemos considerar a existência de um significativo número de estudos realizados no contexto brasileiro no período analisado, que se dirigem aos temas relacionados às políticas de valorização dos profissionais da educação. São vários os enfoques que são trabalhados nesta direção. Verifica-se 
que há uma preocupação contundente quanto à avaliação dos programas de formação nos seus diversos matizes ligando as propostas em curso com fatores das políticas gerais dos governos. Os estudos se apresentam bastante críticos quanto às políticas recentemente adotadas pelo governo baseadas em programas de formação que se caracterizam como aligeirados, que focalizam essencialmente a função ensino, e que se desenvolvem fora do ambiente universitário. São demonstradas, também, grandes preocupações com relação à formação dos professores da educação infantil e das séries iniciais, incluindo uma importante referência à necessidade de se rever a formação dos professores leigos. Em relação à formação, nota-se, também, uma ausência de estudos sobre a preparação ou capacitação de professores para as diversas modalidades de ensino assim como sobre a formação, capacitação e ou aperfeiçoamento dos professores do ensino médio, etapa importante da Educação Básica. Os estudos também demonstraram a necessidade de que as propostas de formação continuada e/ou em serviço levem em conta os saberes dos professores, adquiridos com a sua prática, com o seu cotidiano. Outra preocupação revelada dentre os pesquisadores se refere à formação dos profissionais da educação através dos cursos de Pedagogia, área de formação que se encontra nos dias atuais ainda em estado crítico, na realidade educacional brasileira, levando em conta o longo período de indefinições que caracterizou a elaboração das diretrizes curriculares para esse curso.

Entretanto, é importante considerar a ausência de estudos voltados para outras dimensões da valorização do profissional da educação. Foram poucos os estudos que se dedicaram às questões da profissionalização e das condições funcionais do educador, aspectos cruciais para a concretização dessas políticas. A questão dos planos de carreira, do piso salarial digno, do período reservado para estudos, dos concursos públicos para provimento dos cargos do magistério, dos incentivos para a progressão funcional, além da avaliação do desempenho do professor carecem de novas pesquisas. Neste sentido, observa-se a necessidade de mais investimentos de estudos neste campo do conhecimento. 


\title{
Policies on valuation of profissional education as object \\ of production recent studies
}

\begin{abstract}
This paper consists to show a study about the thematic of research made in the Brazil that has as focus of the investigations the increase the value of politics of education formation, created since the Brazilian Federal constitution of 1988. The analysis is made from consultations the available summaries of theses and theses of master in the available in site of the CAPES, as well as of articles published in periodic that they circulate in the academic community, available in the site of the scielo. The analysis discloses to greater concentration of the studies in the politics and questions related to the formation, scarcity of studies directed toward the professional and functional questions and the necessity of bigger studies directed to the subject. KEYWORDS: Politics of valuation. Formation of professors. Teaching professionalization.
\end{abstract}

\section{Referências}

ABREU, Marisa; BALZANO, Sônia. Progressão na carreira do magistério e avaliação de desempenho. In: RODRIGUES, Maristela Marques; GIÁGIO, Mônica. Guia de consulta para o Programa de Apoio aos Secretários Municipais de Educação - PRASEM III. Brasília: FUNDESCOLA/ MEC, 2001.

AGUiAR, Márcia Ângela da S.; MELO; Márcia Maria de Oliveira. Pedagogia e Faculdades de Educação: vicissitudes e possibilidades da formação pedagógica e docente nas IFES. Educação e Sociedade, Campinas, v. 26, n. 92, p. 959-982, out. 2005. Disponível em: < http:/ /www.scielo.br >. Acesso: 05 out. 2006.

ASSOCIAÇÃO NACIONAL PELA FORMAÇÃO DOS PROFISSIONAIS DA EDUCAÇÃO (ANFOPE). Elementos para uma política global de formação, valorização e profissionalização do magistério. Campinas, 2004. Disponível em: < http://www.lite.fae.unicamp.br/ anfope/menu2/links/arquivos/doc sesu.doc $>$. Acesso em: 05 out. 2006.

BRASIL. Constituição. Constituição da República Federativa do Brasil. São Paulo: Saraiva, 1999.

BRASIL. Lei $\mathrm{n}^{\circ}$ 10.172, de 9 de janeiro de 2001. Aprova o Plano Nacional de Educação. Brasília, 2001. Disponível em: < $\underline{\text { http:// }}$ portal.mec.gov.br/arquivos/pdf/pne.pdf $>$. Acesso em 11 de abril de 2006.

BRASIL. Lei $n^{\circ}$ 9.424, de 24 de dezembro de 1996. Dispõe sobre o Fundo de Manutenção e Desenvolvimento do Ensino Fundamental e 
de Valorização do Magistério, na forma prevista no art. 60, § $7^{\circ}$, do Ato das Disposições Constitucionais Transitórias e dá outras providências. 1996a. Disponível em: < http://wWw.prolei.inep.gov.br/ pesquisar.do $>$. Acesso em: 05 out.2006.

BRASIL. Lei n ${ }^{\circ}$ 9.394, de 20 de dezembro de 1996. Estabelece as diretrizes e bases da educação nacional - Lei de Diretrizes e Bases da Educação - LDB. 1996b. Disponível em: < http://www.prolei.inep.gov.br/ pesquisar.do $>$. Acesso em: 05 out. 2006.

BRZEZINSKI, Iria. A formação e a carreira de profissionais da educação na LDB 9.394/96: possibilidades e perplexidades. In:

(Org.). LDB interpretada: diversos olhares se entrecruzam. São Paulo: Cortez, 2002.

CONSELHO NACIONAL DE EDUCAÇÃO. Resolução CNE/CEB n ${ }^{\circ}$ 03/ 97, de 08 de outubro de 1997. Fixa Diretrizes para os novos Planos de Carreira e de Remuneração para o magistério dos Estados, do distrito Federal e dos Municípios. Disponível em: < http://portal.mec.gov.br/ cne/arquivos/pdf/CEB0397.pdf> Acesso em: 29 out. 2006.

HYPOLITO, Álvaro Moreira. Trabalho docente e profissionalização: sonho prometido ou sonho negado? In: VEIGA, Ilma Passos Alencastro; CUNHA, Maria Isabel da (Org.). Desmistificando a profissionalização do magistrio. Campinas, SP: Papirus, 1999. (Magistério: formação e trabalho pedagógico)

KUENZER, Acácia. As políticas de formação: a constituição da identidade do professor sobrante. Educação e Sociedade, v. 20, n. 68, dez. 1999. Disponvel em: <http://www.scielo.br>. Acesso em: 05 out. 06.

LUDKE, Menga; BOING, Luiz Alberto. Caminhos da profissão e da profissionalidade docentes. Educação e Sociedade, v. 25, n. 89, p.11591180, set./dez. 2004. Disponível em: < http://www.cedes.unicamp.br > . Acesso em: 05 fev. 2006

MONLEVADE, João Antônio Cabral de. Valorização salarial dos professores: o papel do piso salarial profissional nacional como instrumento de valorização do professores da educação pública básica. 2000. São Paulo. Tese (Doutorado) - Universidade Estadual de Campinas, São Paulo.

OLIVEIRA, Dalila Andrade. A reestruturação do trabalho docente: precarização e flexibilização. Educação e Sociedade, Campinas, v. 25, n. 89, p. 1127-1144, set./dez. 2004. Disponvel em < http:// www.scielo.br >. Acesso: 05 out. 2006.

SAMPAIO, Maria das Mercês Ferreira; MARIN, Alda Junqueira. Precarização do trabalho docente e seus efeitos sobre as práticas curriculares. Educação e Sociedade, Campinas, v. 25, n. 89, set./ dez. 2004. Disponível em <http://www.scielo.br>. Acesso: 05 fev. 2006 . 